\title{
Study on Conversations Between Wen Huan and Tan Liu--A Study Based on A New Account of the Tales of the World
}

\author{
Ming Zhang ${ }^{1}$ \\ ${ }^{1}$ School of Chinese Language and Literature, Northeast Normal University, Changchun, Jilin Province, China
}

Keywords: Wen Huan; Tan Liu; conversations.

\begin{abstract}
A New Account of the Tales of the World is a masterpiece of the biographical stories popular during the Wei and Jin dynasties. Characters depicted in the book are not isolated individuals; they form an integral whole with interconnections. There are various complex relationships among characters; the conversations between them can be analyzed from many angles. Wen Huan and Tan Liu are main characters depicted in A New Account of the Tales of the World. In the novel, only a few talks between them are recorded. But their childhood friendship and affinity relationship, especially the latter factor, have certain influences on these conversations.
\end{abstract}

\section{Introduction}

As a book of people's talks and anecdotes, A New Account of the Tales of the World tends to portray carefree, self-centered and unrestrained people. Under the influence of the three thoughts of Confucianism, Taoism and Buddhism, scholars in Wei and Jin dynasties exerted influences on later generations from the perspectives of social activities, behaviors and manners. The book eulogizes the noble demeanor of Wei and Jin period and the elegance of celebrities, and is seen as the "textbook of Wei and Jin celebrities" by Xun Lu. That is to say, study A New Account of the Tales of the World can help you to learn how to be a celebrity. There are various kinds of people in A New Account of the Tales of the World. Some people keep to Confucian ethics, while others pursue the liberation of personality; some people come into the world and pursue achievements, some others retire from the world and live sequestered life; some people like drinking, some are addicted to drugs; some people observe mourning for their parents, some other are not in accordance with filial; some people are eloquent, some are plain and silent. All these unconventional people lead the trend of the times. Wei and Jin Dynasties are the period of self-awakening. Researchers find that during this period, men found themselves. People at that time fully demonstrated their individualities, regardless of continuous wars, cruel ruling class, contradictions inside the ruling class and the sharp contradictions between ruling class and the normal people. As previously stated, in general, it is the result of the interaction of the three thoughts: Confucianism, Taoism and Buddhism. But we cannot deny that people lives in the society; their talks and behaviors cannot be entirely decided by theories and ideological guidance. To a certain extent, social relationship like affinity, friendship, kinship and marriage also influence and restrict their manners. People in society have fixed social circles; people in A New Account of the Tales of the World also have their circles. Tan Liu and Wen Huan are important figures in A New Account of the Tales of the World. In the book, there are ninety three articles involve with Wen Huan's talks, eighty seven articles involve with Tan Liu's talks, and 8 articles involve the conversations between them: article 64 of Chapter Speech, articles 44 and 54 of Chapter Generosity, articles 19 and 20 of Chapter Identification, article 37 of Chapter Evaluation, article 27 of Chapter Appearance and Manner, and article 24 of Chapter Tease and Mock. In A New Account of the Tales of the World, the two characters have interactions.

Tan Liu is a master of academic debate, while Wen Huan is a militarist. How to interpret their conversations is the research topic of this paper.

Tan Liu, whose courtesy name is Zhenchang, was born in Pei Kingdom. His grandfather is Hong Liu; his father is Dan Liu. The biography of Tan Liu can be found in volume seventy-five of The Book of Jin. The courtesy name of Wen Huan is Yuanzi; Wen Huan was born in Qiao Kingdom, 
his biography can be found in volume ninety-eight of The Book of Jin. Wen Huan's father, Yi Huan is the Prefecture Chief of Xuancheng; the story of Yi Huan can be found in volume seventy-four of The Book of Jin. According to The Book of Jin, when Wen Huan was younger than one year old, Jiao Wen observed his appearance and listened to his crying, and praised the baby as "a true hero". Wen Huan's family members were satisfied by Jiao Wen's compliment, and named the young boy as "Wen".

According to The Book of Jin - Wen Huan Biography, Tan Liu and Wen Huan knew each other at an early age. Dan Liu once praised Wen Huan as a figure like Quan Sun and Yi Si-ma. [1] But there's no record on their friendship in The Book of Jin - Tan Liu Biography. The chapter only mentions that Tan Liu is surprised by Wen Huan's talents; he also knows Wen Huan has a heart of disloyalty. According to The Book of Jin, Tan Liu and Wen Huan were in touch with each other when they were young, and they know each other clearly.

In the article 64 of Chapter Speech, the two people are hearing the talking about The Book of Rites. Huan says: "when something sinks in, I feel the Gate to the Secret is very close." Tan Liu replies: "this is not the Extreme; it is the talk of Jinhua Palace" [2] The Book of Rites is one of the Confucian classics, while the "Gate to the Secret" comes from the first chapter of Tao Te Ching: "Reaching from the Mystery into the Deeper Mystery, Is the Gate to the Secret of All Life." It is a symbol of Taoism. From Wen Huan's words, we can found that he has knowledge foundation of Confucianism and Taoism. Tan Liu's answer is also impressive. "Extreme" refers to the ultimate. It comes from Zhuang $\mathrm{Zi}$ - Carefree Journey. "It wondered whether the blue of the sky was its real color, or only the result of distance without extreme end, and saw that the things on earth appeared the same to it." According to The Commentary of Han Shu, the Han Emperor Chengdi often preaches in Jinhua Palace. "Talks of Jinhua Palace" means a scholar is preaching the Confucian thoughts to the emperor. It is obvious that Tan Liu's answer also integrates Confucianism and Taoism. Tan Liu's academic level is higher than Wen Huan's, but they can listen to The Book of Rites together. The object of "talks of Jinhua Palace" is the emperor. According to The Book of Jin, both of Wen Huan and Tan Liu are husbands of princess. They have special identities, and may have the opportunity to hear the "talks of Jinhua Palace".

The article 44 of Generosity records a story. Once, Wen Huan visits Tan Liu, but Tan Liu is still in bed. Wen Huan uses a slingshot to attack Tan Liu's pillow, the projectile smashes on the mattress. Tan Liu is angry and says: "that gentleman, you cannot fight for victory in such way at my house!" Some researchers believe that this is a satire for Wen Huan's defeat in the year 369; some researchers think that Tan Liu means his place is where people talk and debate, rather than military battlefield. Wen Huan, who is not good at academic debates, cannot win here. According to this record, Wen Huan and Tan Liu compete for several times. Wen Huan comes to visit Tan Liu, but Liu refuses to get up; Huan attacks Liu by slingshot, then Tan Liu attacks Wen Huan through speech. It seems that the two people are frolic. Their interactions can be explained from their relationship at early age, and the characters of people in Wei and Jin Dynasties. But a more reasonable reason is that, they are husbands of sisters. In Chinese society, people with this kind of brother relationship can contact with each other equally and make fun of each other, regardless of their ages, social statuses and other factors. Xiao-biao Liu's comment on article 44 of Generosity comes from Zhong Xing Shu. Wen Huan was once the governor of Xuzhou, while Tan Liu was under his governance. Without the brother relationship, Tan Liu could not talk with Wen Huan in that way. According to article 22 of Chapter Speech, Tan Liu was the provincial governor of Danyang. In Jin Dynasty, a regulation prohibiting against being out late at night was implemented. Once in traveling, Tan Liu asked his subordinates to stop and find a hotel to live in the dusk. His subordinates asked him for the reason, Tan Liu said the prefectural governor was tough, and he dared not to walk at night. The book of A New Account of the Tales of the World records some conversations between Tan Liu and Hao Yin; most of these conversations are academic debate. In Article 33, the Chapter of Literature, Liu and Yin talk for a long time. Yin is not good at debating, but he still tries to dispute Tan Liu's opinion. After Yin left, Liu mocks him as a "countryman". Liu is erudite and always advocates talks about metaphysics. He can ridicule Wen Huan, instead of Hao Yin, although Yin's power is less than Wen Huan's. There are other records on 
Liu's attitude towards Huan in A New Account of the Tales of the World. For instance, in the 54 article of Chapter Generosity, Tan Liu, Wen Huan, and Meng Wang visit Zhoushan Mountain. They enjoy the scenery and drink some wine. Then, Tan Liu put his foot on the neck of Wen Huan; Wen Huan cannot bear Tan Liu's behavior, but what he does is raising his hand and push the feet away. How close relationships between them make Tan Liu behave like that? Meng Wang travels with them; can Meng Wang put his feet on the neck of Huan Wen? The answer is no. In the whole book of A New Account of the Tales of the World, besides Tan Liu, no one can put his foot on the neck of others. Moreover, when Tan Liu is drunk, he can only put his foot on the neck of Wen Huan.

In Chapter Identification, article 19, Yi Yu recommends his son, Yuan Yu to succeed his position of prefectural governor of Jingzhou. Officials from the royal court worry that Yuan Yu's loyalty, and ask other officials to recommend a more suitable candidate. So people recommend Wen Huan, but Tan Liu said: "Wen Huan must be able to govern the area of Jingzhou, but I'm afraid the court will be unable to control him at that time." On one hand, it reflects Tan Liu's vision and courage. On the other hand, besides Tan Liu, many other officials also know about Wen Huan's temperament. Yi Yu, Chong He and Chuo Sun also express their attitudes towards Wen Huan, but they cannot speak bluntly that Huan will be out of control if he is appointed as Jingzhou governor. Only Tan Liu believes that Wen Huan will not do harm him due to their special relationship. The special relationship strengthens their mutual understanding. In the article 20 of Identification, court officials estimate that Huan may be unable to defeat Shi Li, the Governor of Shu Area easily. Only Tan Liu holds that Wen Huan must be able to win. According to Liu, he can find Wen Huan's 100 percent confidence from Chu $\mathrm{Pu}$, a kind of a gambling game popular in Wei and Jin Dynasties. The game goes against with Confucian thought, and pursue for the spirit of adventure. Wen Huan is a fan of this game. Article 34 of Chapter Willfulness and Indulgence records, Wen Huan and Dan Yuan are playing the game, throwing chips and shouting, acting as if there is no one else present. Tan Liu must observe Wen Huan's behaviors, and find Wen Huan has adventurous spirit and can seize the moment cautiously.

In the article 37 of Chapter Evaluation, Huan goes to Jiankang by boats. He asks Tan Liu about the progress achieved by Yu Si-ma on metaphysics talking. Tan Liu says that, despite the progress, Si-ma is still in the second level. Then Huan asks who belongs to the first level, Tan Liu said "us". From that content it can be seen, Tan Liu appreciate Wen Huan's talents. In the 27th article of the Chapter Appearance and Manner, Liu comments on the appearance of Wen Huan and says Wen Huan is a hero like Quan Sun and Yi Si-ma. This is a very high appraisal. Liu's comments on Wen Huan reassure our assumption that the satire and between them cannot be explained as Liu's despise or even deliberately insulting of Wen Huan. It is the representation of a special harmonious relationship between them based on their brother relationship.

In the article 24 of Chapter Tease and Mock, Wen Huan wants to go hunting in a snowy day. He goes to visit Meng Wang and Tan Liu firstly. Once Tan Liu sees Wen Huan in the military uniform, he asks, "What are you going to do, the old pest?" Here Tan Liu calls Wen Huan as a "pest" to his face. The expression comes from Analects of Confucius. Rang Yuan is waiting for Confucius; he sits on the ground with legs sprawl like the character of 8 . Confucius is angry and comments, "In youth not humble as befits a junior; in manhood, doing nothing worthy of being handed down; and living on to old age: this is to be a pest". According to the History of the Three Kingdoms, Quan Sun once called Cao Cao as the "old pest" [3], which is definitely a kind of curse. But we believe that the expression can also express banter and affection feelings. For instance, Song-zi Pei once notes The Brief History of Wei, and describes a story as following. Cao Cao wants Xiong-ming Liu to work for him, but Xiong-ming Liu refuses. Xiong-ming Liu goes to Hanzhong area, but afterwards Hanzhong is taken by Cao Cao. Xiong-ming Liu has no place to go but surrender Cao Cao. Cao Cao is delighted for Xiong-ming Liu's surrender; he holds Liu's beard and says, "The old pest, finally I get you!" The expression of "old pest" reflects Cao Cao's fondness. Tan Liu's usage of "old pest" has similar function. Wen Huan is not angry for this expression. He says, if no one goes to fight in the battlefield, how scholars can sit at home talking about metaphysics. He seems to know that the expression is not derogatory, but the representation of love and appreciation. 
Tan Liu can contemn Wen Huan directly, but can he contemn anyone else? In the A New Account of the Tales of the World, there are seventy eight articles involve Tan Liu. Apart from conversations with Wen Huan, more than twenty scholars have talked with Tan Liu, including other relatives such as An Xie (Tan Liu's brother-in-law), and a few people who are not appreciated by Tan Liu, such as Mo Cai and Rou Gao. But Tan Liu never treats them like Wen Huan.

For Wen Huan, not anyone can be presumptuous in front of him. In A New Account of the Tales of the World, there are ninety three articles involve with Wen Huan's talks, except for Tan Liu, no one can behave like Tan Liu in front of Wen Huan. In 58 article of Chapter Generosity, Wen Huan asks Tan-zhi Wang's daughter to marry his son. Though Tan-zhi Wang is Wen Huan's superior at that time, he is afraid of refuse Wen Huan directly. So Tan-zhi Wang finds an excuse that he needs to go home and discuss the issue with his father. Tan-zhi Wang does not agree the marriage between his daughter and Wen Huan's son. Although Wen Huan is a high rank official and is in charge of the military, compared with aristocratic families like Tan-zhi Wang, he still belongs to lower class. It is out of the current concept of social classes. Furthermore, Shu Wang dose not contempt Wen Huan to his face. The 8 article of Chapter Arrogance records the friendship between Wen Huan and Yi Xie, who is in humbler circumstances. Xie Yi often behaves freely regardless of social custom; but he is not as presumptuous as Tan Liu. In the 11 article of Chapter Agreement and Disagreement, Wen Huan is offended by Hong Yuan, an army officer. Wen Huan looks grim, and Hong Yuan is frightened by his response. So, in the A New Account of the Tales of the World, only Tan Liu can talk and interact with Wen Huan in that way. The absolute majority of people contact with Wen Huan respects him. For example, in the article 56 of Chapter Speech, Yu Si-ma, the Jin emperor afterwards, is a general of Fujun Army at that time. He goes to the court with Huan Wen. Both of them insist to go after each other, and Wen Huan has to go ahead of Yu Si-ma. Yu Si-ma's position is higher than Tan Liu, but he highly respects Wen Huan, which shows the special relationship between Tan Liu and Wen Huan. Their special relationship, in addition to teenager friendship, is the brother-in-law relationship, which affects conversations between them. Tan Liu's banter of Wen Huan shows their close friendship and his appreciation towards Wen Huan.

\section{Acknowledgement}

Fund Project: This paper is one of the outcomes of the research, Study on A New Account of the Tales of the World, which is supported by the Foundation of Ministry of Education for Young Scholars, 2014 (Project No.: 14YJC751051).

\section{References}

[1] X.L. Fang, et. al., The Book of Jin, Zhonghua Book Company, Beijing, 1974.

[2] W.Q. Zhang, S.C. Liu, Translation and Annotation of A New Account of the Tales of the World, Zhonghua Book Company, Beijing, 1998.

[3] S. Chen, The History of Three Kingdoms, Zhonghua Book Company, Beijing, 1959. 